\title{
Miedo y Terror en Visión Futura de Chile. 1979
}

Fear and Terror in Chile Future Vision. 1979

Freddy Timmermann

Investigador asociado

CEH-Universidad Bernardo O'Higgins

freddy.timmermannlopez@gmail.com

\section{Resumen}

El presente trabajo analiza la forma en que, en un régimen autoritario cívico-militar, a fines de la década del setenta en Chile, el Estado genera discursivamente una emoción específica, el miedo, en contextos funcionales que permitan desarrollar un proyecto económico de transformación global de la sociedad, el neoliberalismo, en base a presupuestos de la Doctrina de Seguridad Nacional. A partir de miedos derivativos de largo y cercano arraigo emocional, se activan desensibilizaciones e ideologías del sin sentido que desestructuran el anterior sentido de comunidad.

Palabras clave: miedo, terror, neoliberalismo

\begin{abstract}
The purpose of this study is to analyze the manner in which, during an authoritarian civic-military regime in the late seventies in Chile, the State discursively generates a specific emotion - fear-- in functional contexts that allow the development of a global economic transformation project of the society -neoliberalism- on the basis of assumptions of the National Security Doctrine. Based on derivative fears of long and close emotional standing, desensitization and non-sense ideologies are activated breaking the structure of the previous sense of community.
\end{abstract}

Keywords: fear , terror, neoliberalism

Recibido: 20 de Diciembre de 2018 • Aceptado: 20 de Mayo de 2019

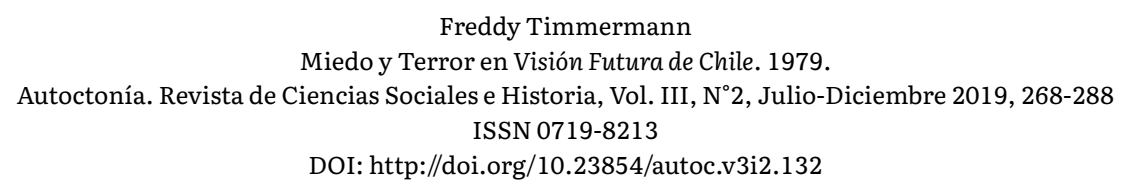




\section{Introducción}

La conciencia histórica se genera para operar contra la incertidumbre temporal (Malerba, 2013: 121-122), constituyéndose en un elemento fundamental que permite al hombre ordenar e interpretar la realidad para, con ello, realizar determinadas acciones. En este ordenamiento concurren elementos afectivos cuya consideración histórica amplía la comprensión del fenómeno humano (Bourke, 2006). Si "sentimos y nos emocionamos de acuerdo con el entorno en el que hemos nacido y en el que vivimos", si las emociones "adquieren significado por la conciencia que el sujeto tiene de las mismas y que irradia en su forma de ver y valorar el mundo" (Camps, 2011: 29 y 36) y si estas operan como mediadores psicofisiológicos de la razón para orientar la aceptación de la realidad contextual, $\mathrm{y}$, por lo tanto, son intersubjetivas y fisiológicas a la vez, se debe considerar el estudio de los contextos emocionales que las originan para establecer la necesaria conciencia histórica epocal del objeto historiográfico en estudio (Stearns, 1985; Zaragoza, 2013; Plamper, 2014). Se habla del afecto, que "ha eclipsado a la razón como el vehículo epistémico dominante para la delineación de la forma y los límites del conocimiento y la construcción de significados culturales" (Reber, 2012: 94). Para Moraña, pese a ser una forma desterritorializada, fluctuante e impersonal de energía que circula a través de lo social sin someterse a normas ni reconocer fronteras, no puede deslindarse de los niveles éticos, estéticos y políticos que configuran sistemas interdepen- dientes de significación que se sostienen entre sí y se proyectan como totalidades de sentido sometiéndose a incesantes procesos de interpretación. Si bien afecto y miedo no son solamente un aspecto del mundo, sino es el mundo todo entendido éste como universo de potencialidad afectiva", lo fundamental para el presente interés es el proceso por el cual el afecto pasa "de la virtualidad al ser-en-acto" (2012: 320-323). Es decir, se convierte en acción histórica, que aquí se estudia en función de una emoción específica, el miedo, en un contexto particular, la existencia de un Estado cívico-militar, que procura desarrollar un proyecto global de transformación socio-política mediante la producción discursiva de miedo y terror.

\section{Emoción, miedo, historia}

La emoción está presente en todo proceso psicológico, siendo una experiencia afectiva (Pacheco, 2011; Barrancos, 2009). Abarca sistemas de respuestas cognitivos, fisiológicos y conductuales, que no necesariamente operan en forma sincrónica. Supone una cualidad fenomenológica característica. Sus funciones adaptativas preparan al organismo para actuar de acuerdo a lo que exigen las condiciones ambientales, "movilizando la energía necesaria para ello" y "dirigiendo la conducta (acercando o alejando) hacia un objetivo determinado"; sus funciones sociales facilitan la aparición de conductas, como expresar la emoción apropiada, central para los procesos de relación interpersonal, e influyen los aspectos motivacionales que le otorgan a ésta direc- 
ción e intensidad (Choliz, 2005: 3-6).

Las emociones poseen indudablemente una dependencia biológica (Maureira-Sánchez, 2007: 183-189), pero interesa aquí proyectar su construcción social. Sin duda, la velocidad fisiológica inicial de la emoción es instantánea ${ }^{1}$, y solo una vez que, en el caso del miedo, opera más ampliamente definida en función de una adaptación social, esta tiene duraciones más prolongadas. Allí, los elementos cognitivos y contextuales son centrales para su mantención. También los elementos fisiológicos siguen operando, como lo ha demostrado Feierstein refiriéndose a los procesos de desensibilización neuronal que generan pactos denegativos e ideologías del sin sentido, es decir, que activan circuitos sociales donde la propaganda oficial, el control de la prensa, la represión política, la miseria económica y el rumor constituyen un todo estructural que impone una percepción de realidad en que la identidad sociopolítica se transforma, ya sea cortando al revés (Escalante, 1990: 26-27), o realizando una inversión de sentido (Donatello, 2010: 145-162), etc., configurando un proceso histórico que impone un contexto emocional específico de desarrollo temporal extenso (Timmermann, 2015).

No existe acuerdo sobre la mayor o menor incidencia de las variables que generan la emociones, que van desde las posiciones evolucionistas y psicofisiológicas hasta las que privilegian las estructuras neurológicas centrales, aspectos conductuales y variables cognitivas (Chóliz, 2005: 23-33). Sin embargo, sostener la existen- cia de un patrón único o estable al respecto sería menoscabar la capacidad de respuesta del hombre antes contextos diferenciados y cambiantes. Por ello, se piensa que las variables mencionadas por Chóliz pueden operar individual o integradamente en combinaciones distintas, de acuerdo a la necesidad contextual. Para el presente interés, la variable cognitiva es de primera importancia ${ }^{2}$. El estudio del lenguaje es central a la hora de establecer cómo una existencia significativa lleva a prácticas específicas. Se cree en éste estudio que los afectos (que posibilitan ante la realidad una primera impresión en que las situaciones se valoran como alto-bajo o positivo-negativo), los sentimientos (que constituyen la toma de conciencia de que se experimenta una emoción) (Maureira-Sánchez, 2007: 184) y la emoción (aun cuando generalmente operan integradas a otra u otras), como el miedo en este caso, permiten comprender desde los contextos la forma en que las percepciones de realidad vinculadas a ellas -inseguridad/seguridad en este estudio- se convierten en significados debido a la acción específica adaptativa que se debe realizar. De esta forma, en esta investigación se integra al cuerpo, que por medio de las emociones se establece como mediador de la acción histórica. El discurso otorga un significado al contexto social, preparando una acción en que el cuerpo por medio de las emociones calibraría este significado, según la energía y elementos psicofisológicos particulares de que cada uno dispone. Por ello "el análisis cultural considerando la carga emocional de los significados culturales es útil para distinguir cuando estos se adquieren en 
el nivel de mero reconocimiento (se conocen y se repiten, pero sin el asentimiento personal y sin consecuencias para la vida práctica) y cuándo se asumen como significados sobresalientes cognitiva y emocionalmente (son apropiados e internalizados y generan compromisos)". Las emociones "nos alertan sobre las cosas que importan y por qué importan" siendo creadas y sostenidas en interacciones intersubjetivas, desencadenándose por cogniciones, basándose en un objeto intencional, siendo formas intrínsecas de compromiso y juicio evaluativo no exentas de evaluación y juicio evaluativo. Están ligadas al orden social en una comunidad, pues implican la asunción de patrones socioculturales determinados por la experiencia, manifestados en situaciones sociales específicas (Rodríguez, 2008).

El miedo es una emoción vinculada a conocimiento, una experiencia que genera un efecto emocional variable debido a la interpretación de una vivencia, objeto o situación como potencialmente peligrosa, cuando su control o anulación es incierta. Con ello, se relevan sus elementos constitutivos como emoción, psicofisiología, interpretación, peligro/amenaza, incertidumbre/ dolor, inseguridad/seguridad, control/salida, y tiempo de desarrollo, lo que permite analizarlo historiográficamente y determinar sus ritmos. Cada uno de los elementos mencionados no necesariamente opera en forma sincrónica con los restantes. Se produce una modificación de la racionalidad de percepción, lo que genera incertidumbre y con ello dolor, hecho que pasa a constituir el centro del problema a resolver: libe- rarse del dolor padecido, enseñado y aprendido (Chóliz, 1994: 77-88), constituyéndose el miedo en un estado de desorientación, de ceguera afectiva y constituye el problema más importante de la vida; es sufrimiento psíquico (Diel, 1995). Por ello es que el temor "actualiza un proceso profundo de ritualización con el fin de destruir el suspenso y la incertidumbre propia del futuro" (Korstanje, 2011). Un elemento central es que se experimenta una situación de inseguridad, por lo que su desarrollo temporal transitará hacia la búsqueda de un contexto de seguridad.

La psiquiatría ha demostrado que la necesidad de seguridad es fundamental en el ser humano, pues éste no se desarrolla en la incertidumbre. Aun cuando "es estructural en nosotros", el conocimiento del pasado "parece demostrar que está necesidad se reforzó con la afirmación de la modernidad", agregando que "nuestros antepasados eran más resignados y fatalistas que nosotros frente a las desgracias y riesgos que les rodeaban permanentemente" (Delumeau, 2002; Bauman 2004). En la modernidad, se procura controlar la inseguridad. Para Foucault, el concepto de seguridad, a diferencia del principio disciplinario, que se aplica sobre el desvío a la norma jurídica para controlar los cuerpos, regula de antemano los factores que infieren en la seguridad interna, es decir, enfrenta la incertidumbre. Por ello, su función es crear el consenso necesario para aceptar la situación dentro de ciertos límites que llevan a aislar la peligrosidad (Korstanje, 2013). Se ha visto que en Chile, desde la década del sesenta o poco antes, se comienza a 
experimentar una disminución de la seguridad, especialmente política (Frühling, 2002: 299309). En el mundo ésta disminuye desde 1938 y en EEUU desde 1953 (Delumeau 2002). Esta necesidad de seguridad lleva a que se utilicen diferentes elementos culturales para su propia protección (Korstanje, 2011) porque, para Bauman, "Tememos aquello que no podemos controlar, denominandoincomprensión a esa imposibilidad de control; cuando hablamos de la comprensión de algo, nos referimos a nuestro conocimiento técnico sobre cómo abordarlo... Lo que no somos capaces de manejar nos es "desconocido", y lo "desconocido" nos asusta". Para él, miedo es el nombre que damos a nuestra incertidumbre e indefensión (2007). Es importante reiterarlo: si esta amenaza se controla, se genera un vínculo miedo-conocimiento que posibilita una acción de control o salida de él. Por ello el miedo genera efectos como fenómeno individual pero también social en cuanto a "significación subjetiva y política” (Lira-Castillo, 1991). Es un fenómeno individual e intersubjetivo. Los miedos comienzan en el cuerpo (Gonzalez, 2013: 1429-1447) y se desarrollan a partir de él, como cualquier otra forma de comunicación y de socialización. Produce transformaciones fisiológicas amplias (Shkurko-shkurko, 2014: 99-110; Maureira-Sánchez, 2011). La desensibilización precisa la forma en que opera esta racionalidad del miedo cuando aquello que lo genera no es controlado o anulado, que es lo que ocurre en el Régimen Cívico-Militar (RCM) 3 cuando las FFAA se convierten perceptiva y factualmente para amplios sectores de la población en un objeto y situación que les genera inseguridad. Feierstain plantea la existencia de una desensibilización, generada por "el sometimiento permanente a un estímulo doloroso, ante el cual no hay posibilidad de acción (inviabilidad de la evitación-huida o la confrontación)". La respuesta adaptativa es "el apaciguamiento del conjunto de transmisiones sinápticas vinculadas al dolor, en tanto la única finalidad adaptativa del dolor se vincula a constituir un sistema de alerta para la acción". "Si la acción se encuentra obturada, entonces todo el sistema nervioso de comunicación del dolor debiera sufrir una lenta pero sostenida adaptación a fines de ir deprimiendo la intensidad de la transmisión". Para la creación de memoria de largo plazo -proceso central, por ejemplo, para desarrollar miedos, miedos derivativos o para refundarlos- se requiere crear nuevas vías de comunicación. Existen dos modos en que ello ocurre: por la repetición y por la afección emocional, que operan genética y cerebralmente en forma distinta. La mayoría de estas transformaciones, afirma, "se dan a nivel no consciente", pero la memoria "es un proceso constructivo y no literal, [en] que las representaciones tienen un sentido adaptativo vinculado a la búsqueda de sentido". Este sentido "permitirá dar cierta eficacia a las acciones -la posibilidad de realizar los fines deseados- y cierta estabilidad y permanencia a los procesos de construcción de identidad, que como tales requieren altos niveles de coherencia interna" (Feierstein, 2012), es decir permitirá arribar a una situación de seguridad, si lo proyectamos operando desde una situación de miedo. Al anular la experiencia de inseguri- 
dad padecida se produce un fenómeno transubjetivo, el pacto denegativo, que son modalidades narrativas que emergen y van ganando hegemonía para lograr articularse profundamente. Por ello es que la desensibilización "también opera a nivel de la subjetividad individual" pero "con efectos de acumulación histórico-social". Esta "acumulación desensibilizadora" "cuando refiere a hechos que afectan a grupos importantes de la población, se articula histórica y socialmente como una ideología estructurada y estructurante de la desensibilización, como instauración ideológica de la falta de sentido construida en la imposibilidad de abordaje de lo traumático". Es una ideología del sin sentido, "basada en la renuncia consciente e ideológicamente justificada a toda búsqueda de estructuración de la propia identidad, articulada algunas veces con el cinismo, otras con el nihilismo, las menos con la sátira o la burla" (Feierstein, 2012). Para muchos, el concretar este pacto denegativo fue lo que generó su tránsito, a partir de la década del sesenta, hacia percepciones que les permitieron aceptar contextos cambiantes inseguros que establecían condiciones de convivencia diferentes. Allí la inseguridad y el miedo escalan a niveles mayores y la permanencia de una identidad social está amenazada. Es parte de lo que también experimenta la Iglesia Católica.

La interpretación de un objeto como inseguro o peligroso puede realizarse a partir de una experiencia anterior de miedo, el que de esta forma es refundado, aunque posiblemente modificado en parte. Este miedo del pasado es el miedo deri- vativo, "el sedimento de una experiencia pasada de confrontación directa con la amenaza" que "puede ser disociado en la conciencia de quien lo padece", pudiendo interpretarlo en relación con cualquiera de los tipos de peligro, con independencia de las pruebas de las contribuciones y la responsabilidad relativas a cada uno de ellos. Por ello, las reacciones defensivas o agresivas resultantes destinadas a atenuar el temor pueden ser separadas de los peligros realmente responsables de la presunción de inseguridad (Bauman, 2007: 11-12). Antes objetos, sujetos o situaciones de peligro o amenaza similares a las anteriormente experimentadas, se activan.

El miedo procede de la presión que la realidad existente o imaginaria ejerce sobre nosotros, pudiendo evadirse, encontrar un control o salida por medio del pensamiento trascendente o tecnología discursiva. Las dos instancias pueden operar conjuntamente y ser producidas discursivamente, pero sus efectos individuales y sociales dependerán del tiempo en que el objeto, vivencia o situación que se interpreta como peligroso sea anulado o controlado, es decir, de la rapidez o lentitud con que se encuentre una salida del miedo. Mientras ello no suceda, el individuo, estará sumido en incertidumbre y, por lo tanto, experimentará un determinado tipo de dolor que lo sumirá en una situación contextual de miedo. Políticamente ello es central por cuanto el miedo puede prolongarse indefinidamente en función de su producción en cuanto psicotecnología. También si se comparte socialmente una determinada percepción de un objeto, vivencia 
o situación cuya existencia puede ser también socialmente estructural, no necesariamente producida (Timmermann, 2005 y 2007). Interesa aquí referir su producción política en un contexto específico autoritario, el de Chile, en la etapa fundacional del RCM en su período final, desde 1978-79, cuando se procuraba neoliberalizar desde perspectivas globales a la sociedad chilena. Esta etapa específica recoge la maduración previa de procesos de desensibilización, pactos denegativos e ideologías del sin sentido en una parte importante de la población (Timmermann, 2015). Es en éste contexto donde opera la producción de miedo de Visión Futura.

\section{Doctrina de Seguridad Nacional y mercado}

La producción de miedo no opera sino en función de un contexto funcional de inseguridad, que también puede ser producido. Lo es para la elite del RCM, porque el año el conflicto en torno al Beagle con Argentina entra en una fase de amplias tensiones militares, pudiendo para Chile concretarse la Hipótesis Vecinal 3, enfrentar a los tres Estados limítrofes al mismo tiempo. También, los familiares de los detenidos desaparecidos ocupan tres iglesias en Santiago y las oficinas de UNICEF, iniciando una huelga de hambre y un grupo marcha por el centro con carteles que reclaman por 618 desaparecidos, refiriendo la prensa nacional por primera vez el tema ((Harrington, 1987: 299-300). Pinochet deberá tomar una decisión para sortear las presiones de Estados Unidos relacionadas con el asesinato de Letelier. Primero, decide sacar a Leigh, Coman- dante en Jefe de la Fuerza Aérea, de la Junta militar para despejar el frente interno, luego de lo cual la élite civil vuelve a apoyarlo, y a mediados de 1979 la Corte Suprema rechaza las solicitudes de extradición de los agentes de la DINA solicitadas por Estados Unidos. A fin de año, Juan Pablo II ofrece mediar en el conflicto con Argentina, lo que es aceptado por ambas partes. Pinochet y la élite militar nuevamente han tomado el control de sus espacios de poder, situación que Visión Futura de Chile procurará legitimar para lograr concretar el diseño de una Constitución donde se concrete el tutelaje de las FFAA sobre la sociedad civil. Al mismo tiempo, el neoliberalismo, que se desarrollaba desde 1975, alcanza su punto mayor de influencia, generando espacios de seguridad a las elites civiles y militares del régimen. La transformación de la mentalidad militar para absorber el neoliberalismo fue relativamente rápida, por aspectos concretos, como el impacto de los niveles de consumo ofrecidos por el modelo y el mayor presupuesto y capacidad de modernización de sus instituciones con que contaron, pues con anterioridad las "planificaciones globales" de los gobiernos de Frei y Allende habían reducido el presupuesto de Defensa. Los éxitos que el modelo mostraba se acentúan por la hegemonía alcanzada por el discurso neoliberal al desaparecer toda prensa opositora prácticamente. Hay también elementos en el neoliberalismo que tenían arraigo en la cosmovisión castrense, como el tema de la eficiencia -cumplimiento del deber, logro de un objetivoy la relevancia de la modernización -preocupación por el tema del desarrollo- influida en su re- 
cepción por el cambio en el cuerpo de oficiales, pues desaparecieron los existentes hacia 1973, imbuidos en los antiguos paradigmas estatistas, siendo dados de baja o pasados a retiro por la Juntas Calificadoras desde 1974. Los nuevos tenían menos internalizado los parámetros anteriores pues habían acudido a la Academia de Guerra, ya en manos de los teóricos de la Doctrina de Seguridad Nacional y del neoliberalismo donde fueron uniformados ideológicamente. Ahora, el mercado es la expresión económica que representa la impersonalidad en el mando, pues las decisiones las somete a reglas objetivas e uniformes realizando en su esfera la igualdad de todos (Valdivia, 2003: 139-149).

Para la derecha, el neoliberalismo introduce modificaciones en su forma histórica de hacer política, que, desde la década del cuarenta, evoluciona hacia el pragmatismo, por el deterioro de sus componentes ético-doctrinarios y político-defensivos, sin proponer una visión global del mundo o una defensa de una alternativa de sociedad. El neoliberalismo, al contrario, otorga una gran importancia a la acción ideológica y posee una visión utópica de una autorregulada por el mercado. Las estrategias ideológico-culturales desempeñan un papel crucial. Desde 1978 se diseñan y ejecutan para sensibilizar al hombre medio y a las élites por medio de un discurso racional sobre la construcción de una nueva sociedad por medio de políticas concretas y planes de reforma. Se procuraba concientizarlo. Se usaban medios de comunicación de masas, especialmente el diario El Mercurio, las revistas
Qué Pasa, Ercilla, los que en sus líneas editoriales popularizaban los conceptos neoliberales. Los neoliberales adquieren y controlan organismos académicos y centros de investigación (Vergara, 1985: 173-175). También en el plano educativo se procura generar transformaciones en esta dirección, porque para ellos la educación debería formar personas que supieran leer, escribir y hacer cálculos básicos, según planteaba Milton Friedman, retirándose el Estado de su administración, que quedaría en manos privadas.

\section{Los miedos. Marxismo y democracia liberal}

En Visión Futura no existe duda que el poder está radicado en las Fuerzas Armadas y de Orden cuya "intervención" "no sería transitoria" porque así no se "alejarían" "del verdadero sentimiento y voluntad de la ciudadanía" ni de su "esencia", cuya "misión principal es la defensa y preservación invariable de los valores patrios" (21). Es "Buscando las raíces en el pasado, pero mirando siempre hacia el futuro, [que] hemos diseñado las proyecciones de este nuevo Estado democrático" (4). Pinochet habla de "afianzar las bases de esta nueva independencia" (52). Aparece una posibilidad de alcanzar una dispensa de los miedos derivativos al percibirse un punto de llegada de cuando había acontecido desde el 11 de septiembre de 1973. El polo negativo que permite construir un enemigo y alrededor del cual giran los miedos derivativos sigue siendo el marxismo, resaltando la existencia de un enemigo externo que puede aparecer en cualquier momento y lugar. Se expresa: "Enfrenta- 
do al dilema real de nuestro tiempo, la opción entre el totalitarismo bajo control soviético y la libertad, el Gobierno chileno ha optado resueltamente por esta última" (41); que "Lo ocurrido durante el trienio 1970-1973 es prueba del error suicida que significa legitimar jurídica y políticamente aquellas doctrinas que contravienen y destruyen la médula misma de la comunidad nacional y propugnan el enfrentamiento fratricida sin detenerse siquiera ante la posibilidad de una guerra civil". "Es desde todo punto de vista imposible que coexistan en el seno de una misma comunidad dos concepciones intrínsecamente antagónicas, como ocurriría de permitirse la actividad legal, dentro de una democracia, de corrientes totalitarias, pues estas, fatalmente, llevan a la destrucción de la primera" (30-32). Poco antes se había sostenido que "La aplicación en Chile, durante casi medio siglo, de las fórmulas tradicionales del sistema clásico de la vieja democracia" "condujo, en 1970, al advenimiento de un sistema estatista... sin ocultar en momento alguno sus pretensiones de establecer una estructura totalitaria, similar al modelo soviético, el cual era su principal fuente de apoyo ideológico, político y financiero" (17-18). Quienes aceptaron el Estatuto de Garantías Constitucionales para "detener o controlar esa evolución" "dieron prueba, bajo el régimen marxista, de su impotencia e incomprensible falta de visión" (18). Agrega que Chile, "no puede permanecer aferrado a posiciones dogmáticas que, aplicadas en el pasado, no solo no consiguieron hacer salir al país de un subdesarrollo que podemos y debemos dejar atrás, sino que, además, probaron larga y reiteradamente ser insuficientes para obtener los benéficos resultados que la teoría pretendía atribuirles" (27). Especifica algunos aspectos políticos que considera negativos al sostener que "La sola dictación de un sistema de normas no permite que una auténtica democracia exista y se mantenga establemente, ni está garantizada la manifestación real de la voluntad popular por la promulgación de leyes relativas al sufragio popular o a los registros electorales. Todo ello es sobrepasado implacablemente por el estatismo totalitario, que anula la libertad" (28). Una sociedad "que verdaderamente desee vivir en un régimen de libertad, debe ser capaz de hacer coexistir equilibradamente ambas realidades, unidad y discrepancia. En Chile, tal consenso mínimo desapareció como consecuencia del avance y posterior asunción al poder del marxismo soviético" (29). El "nuevo sistema" debe "asegurar la libertad" y "preservar" a la Nación "de una nueva infiltración soviética, mediante restricciones jurídicas que señalen virtuales límites a la discrepancia cívica, y protejan al sistema democrático como forma permanente de vida" (30). Finalmente, se afirma que "[e] $\mathrm{s}$ tan grande y grave el peligro permanente, que no entendemos terminada nuestra misión y nuestro deber con la sola dictación de una nueva constitución, por elevada que sea la perfección técnica de sus normas. Velaremos por su expedita puesta en vigencia y funcionamiento. Resguardaremos la consolidación de la nueva institucionalidad durante un período breve pero suficiente, hasta verificar que, dentro de lo previsible, ella sea sólida y fuerte, para con- 
trarrestar el ataque totalitario" (49). La Unidad Popular es aún el enemigo que ordena la producción de sentido. No se apela a elementos trascendentes 4 para lograr movilizar emociones -como ocurría hacia los años 1973-1975- pues es en el plano inmanente donde se centra el interés, en lo mediato, en la estructura política que pronto se instaurará mediante la Constitución de 1980, que opera como la gran dispensadora de los elementos que generan inseguridad. La Unidad Popular es una vivencia cuya memoria se procura revivir para producir una legitimación del RCM que anule esta posibilidad de un retorno a la democracia liberal, a su vuelta, y se usa a la Unidad Popular para instalar una imagen negativa de ella. Por supuesto, la proyección utilizada es el régimen soviético.

\section{El Presidente de la República}

También se teme a la élite civil. Es el otro peligro que menciona Visión Futura, la oposición que existe al Presidente del país. Expresa el documento que “... desde el inicio mismo del régimen portaliano hasta hoy, los grandes enemigos del Presidente como institución, y de su poder, han sido los grupos de presión y las oligarquías. Estas han querido siempre gobernar por sí y para sí, viendo un obstáculo en su autoridad..." (6).

Cuando se describe el "parlamentarismo", se menoscaba a la "aristocracia [que] gobernaba plenamente a través de los partidos" que, al perder "sus cualidades iniciales de austeridad y sobriedad, decayó en oligarquía” (7), la que “asen- tada en el poder perdía su tiempo y el del país, levantando y derribando bizantinas combinaciones políticas y gabinetes ministeriales, que en algunos casos solo duraban días y en otros, semanas". Así, "El estamento alto de la sociedad que tan positivo fuera para el país mientras prestó su apoyo y aceptó el régimen presidencial portaliano, a partir de su predominio indiscriminado se transformó en negativo para los intereses de Chile, convirtiéndose en una fuerza política que buscaba gobernar exclusivamente para él, anulando casi por completo al Presidente de la República" (11). Lo realizado por la “intervención" militar de 1924 "fracasó por no haber reglamentado de manera eficaz la acción de los partidos políticos" que "hipertrofiaron el poder en forma desmesurada, llegando a sobreponerse al Presidente y al propio Congreso, ya que ni la Constitución ni las leyes definieron cuáles eran los límites de esos grupos" ni "reglamentaron" "la disciplina interna de los partidos políticos, de manera que éstos, cada vez que alcanzaban el poder, brindaron un espectáculo de inestabilidad, frivolidad y pequeñez, peor que, en los mismos aspectos, había dado hasta 1925 el parlamentarismo". También, "se omitió regular la responsabilidad de los partidos" lo que generó "los acuerdos más censurables y lesivos para el país que ellos adoptaron, sin que nadie estuviese en condiciones de pedirles o exigirles cuenta de tales procederes". No se "reglamentó" su financiamiento, con lo que "se abrieron las puertas a las más oscuras corrupciones" (11-12). Desde 1925, el país fue "esclavo y víctima del régimen de partidos políticos". Surgen "gremios privi- 
legiados, que por su poder económico o por su caudal de votos, o por ambas circunstancias a la vez, se convierten en la base de sustentación de determinados partidos políticos; y surgen, asimismo, máquinas electorales, que combinando el cohecho, la presión administrativa, el fraude y la violencia, controlan políticamente regiones, con lo cual eligen sus diputados y senadores, convirtiéndose, con ello, en una fuente autónoma de poder" (12-13). Los "partidos populares" son considerados "particularmente trágicos" porque, además de lo mencionado, "usan como arma de conquista de votos a la demagogia, destruyen la unidad nacional, avivando la lucha de clases, odios y la promesa de paraísos imposibles". Uno de ellos se "entrega en manos de Moscú en el año 1921", el "Partido Comunista de Chile", "famoso" por su "servilismo" a la Unión Soviética, "sumiso" a Moscú durante la "Primavera de Praga" (13). Se sostiene que las Fuerzas Armadas van a "introducir un cambio integralmente renovador" en el "régimen político partidista por estimar que éste es el que paraliza el progreso nacional y porque han comprobado que se ha llegado a un total agotamiento del sistema democrático tradicional". Antes, el pueblo, "al manifestarse electoralmente", tendió a elegir Presidentes "fuertes" que luego "la maquinaria partidista se encargaba de anular y de inhibir" (17).

La proyección de autoridad, sin embargo, va más allá la mera reingeniería política, ello, porque una posibilidad de evasión del miedo es el pensamiento mágico, que permite al individuo recuperar en su imaginación el control de la realidad que ha perdido. En este sentido, la tecnología cumple la misma función que la magia. En el primer caso, el recorrido es natural. En el segundo, es sobrenatural (Mongardini, 2007: 39). Ambos elementos operan en la percepción de realidad ligada a "lo portaliano" -elemento central del idealismo que el RCM sigue-: magia en cuanto a que el Presidente de la República es portador de una esencia o tradición nacionalista trascendente. También en cuanto caudillo que posee un don sobrenatural (Ramos, 1985). Tecnología en cuanto a proyectarlo como artífice de y desde un contexto donde impera la matriz mental neoliberal, supuestamente técnica, científica, eficiente. Se resalta en Visión Futura al "Presidente de la República" pero no a los partidos políticos. Para ello, se expone el desarrollo histórico de Chile" desde un "período más brillante" hasta la pérdida de él, por la "oposición" de los "grupos de presión y oligarquías" a su poder (6-7), lo que lleva a la "etapa más estéril" de la historia del país, el "parlamentarismo" (711). Los argumentos son generalizaciones basadas en posiciones contrastantes donde existe una figura que daña al país y otra que lo salva. No se dan más detalles respecto a las razones de ocurrencia de estos hechos, pero se mencionan las acciones de los "grupos de presión y oligarquías". Luego, se sostiene que, al "poner término" al gobierno de la Unidad Popular, las Fuerzas Armadas "asumen" una "responsabilidad integral, por cuanto su acción tenía por objeto recuperar para todos los chilenos los derechos y las libertades al borde de la extinción. Pero esta 
vez no sería para dejarlas entregadas al juego de las oligarquías partidistas que nos condujeron a la crisis" (20).

Se sigue temiendo a la política, a la democracia liberal, pero se amplían en el tiempo los acontecimientos en que se sustenta su deslegitimación, extendiéndola más allá del gobierno de la Unidad Popular. La dispensa del terror se centra en la legitimación de un proyecto que será dirigido por el Presidente de la República, fortalecido desde todo punto de vista, visualizando en él a un nuevo Portales. Lo "portaliano" evidencia que la principal forma que da salida a los miedos derivativos estudiados sigue siendo el uso de la violencia, la amenaza política constante. No existe otra perspectiva y hasta la insistencia en un presidente-caudillo apunta a ello. La crisis está en el futuro, no en el presente y es el uso de la Doctrina de Seguridad Nacional, más que de la política, lo que otorga seguridad a la élite estudiada. Ello no ausenta, discursivamente, el uso del recurso trascendente más allá de la "concepción cristiana", e incluso del nacionalismo al proyectar la imagen de un caudillo, figura prepolítica tal vez, que, como se expresó, busca conciliar magia y tecnología con esencialismo y neoliberalismo.

\section{El estado de Derecho de la violencia}

El uso de la violencia se enfatiza indirecta y directamente en Visión Futura. No se insiste mayormente en los anteriores enemigos de los primeros años del RCM -la Unidad Popular, el marxismo cubano y soviético- . Ya se ha alcanzado la suficiente seguridad respecto a su control. Si bien no se refiere a la "sanción drástica" de la Declaración de Principios de 1974, se afirma sí que no "tomar medidas preventivas" frente a esta "agresión soviética constituiría, por omisión, violar gravemente los derechos humanos más esenciales" (33). También, en un subcapítulo titulado "Principios inspiradores del régimen portaliano", donde el tema central es el carácter "autoritario" e "impersonal" del gobierno, se expresa que en 1830 "se instauró un Gobierno autoritario", que Portales -“ese hombre de genio"-poseía un "don de mando”, una "poderosa mano" con la que "ejerce" el "principio de autoridad" (4). Tampoco hay referencias a la Seguridad Nacional, salvo para sostener que un "deber ineludible del Estado" es "proteger debidamente la seguridad de las personas" (33). Pero el tema de ninguna forma es dejado de lado por el RCM, pues en el Mensaje Presidencial del año 1979 se menciona, respecto a la Academia Superior de Seguridad Nacional, que en "relación con las tareas específicas asignadas este Alto Instituto ha constituido las comisiones de estudio abocadas a establecer las bases para la formulación" de una "Política de Seguridad Nacional para Chile, de acuerdo a la Declaración de Principios de la H. Junta de Gobierno y orientada por el Objetivo Nacional" (1979: 94). La Constitución de 1980 tendrá una presencia significativa de la "seguridad nacional" en la forma en que estructura jurídicamente al régimen. Sostiene en el artículo $1^{\circ}$ que "Es deber del Estado resguardar la seguridad nacional”, concepto que no se define 
en la Comisión de Estudios de esta Constitución. Quienes representan el sistema de seguridad nacional no son elegidos por la ciudadanía, siendo organismos de composición hegemónicamente militar quienes lo hacen (Presidente de la República, Consejo de Seguridad Nacional, Estado Mayor de la Defensa Nacional, Consejo Asesor y Político Estratégico, Consejo Asesor de Seguridad Interior). En el nivel de ejecución, queda entregada a los ministerios. Es el rol de las FF. AA. (artículo 90). Más aún, pues el artículo 79 no establece que la Corte Suprema deba vigilar a los Tribunales Militares, en tiempos de guerra, para evitar sus abusos de poder. En función de la tipificación arbitraria que se realizó luego del GCM del "estado de guerra", ello implica un grave riesgo para el adecuado respeto de los derechos legales del ciudadano. El artículo 96 establece que el Consejo de Seguridad Nacional "requerirá como quórum para sesionar el de la mayoría absoluta de sus integrantes", lo que le otorga una autonomía que sobrepasa, en cuanto a su función, solo el "Asesorar al Presidente de la República en cualquier materia vinculada a la seguridad nacional en que éste lo solicite", según afirma el citado artículo. Puede incluso autoconvocarse. Otras de sus atribuciones son integrar el Senado con "Un ex Comandante en Jefe del Ejército, uno de la Armada, otro de la Fuerza Aérea, y un ex General Director de Carabineros que hayan desempeñado el cargo a lo menos por dos años, elegidos por el Consejo de Seguridad Nacional" (artículo 45). Además, el Tribunal Constitucional estará compuesto por "Dos abogados elegidos por el Consejo de Seguri- dad Nacional" (artículo 81). También el artículo 40 establece que debe acordar con el Presidente de la República los diversos estados de excepción constitucional. Lo anterior se refuerza al establecer que la organización de las FF. AA. es materia de ley en la Constitución de 1980. Su funcionamiento es entregado al Presidente de la República que puede "Disponer de las fuerzas de aire, mar y tierra, organizarlas y distribuirlas de acuerdo con las necesidades de la seguridad nacional" (artículo 32). Así, se consolida legalmente la tutela militar del poder político, se concreta legalmente el monopolio del ejercicio de la fuerza y se institucionaliza una percepción distinta de la Doctrina de Seguridad Nacional, funcional al proyecto neoliberal y a las hegemonías del poder de la Junta y de Augusto Pinochet y el Ejército. Se afianza con ello la funcionalidad jurídica del Gran Terror pues este miedo "requiere de instituciones totales, con uniformidad normativa, con privilegios y castigos, que reemplace los mecanismos normales que operan en la contención de estos en un régimen democrático" (Mongardini, 2007: 114). Con la aprobación de la Constitución de 1980, pese a la poca transparencia del proceso, el orden derivado del uso de la fuerza y del terror alcanza una institucionalización legal. Es la consolidación del RCM la que se interpreta como su legitimación ciudadana. Las élites que lo sostienen, pese a sus disensos, liberan miedos. Los militares, aquellos nacidos al concretar el GCM destituyendo a un gobierno democráticamente elegido y usando la fuerza en ello. La derecha neoliberal alcanza la seguridad al dar un marco que no pertuba el desarrollo eco- 
nómico y el gremialismo excluye la soberanía popular. Todos los adherentes al RCM se sienten seguros porque el tutelaje militar constituye un recurso de amenaza política, ahora legalmente establecido, para garantizar la permanencia de un nuevo orden que protege del marxismo. Para la mayoría de la restante población, en grados variables, no hay salida posible de sus miedos, sino adentrándose, aunque sea parcialmente, en los pactos denegativos y en la construcción de una ideología del sinsentido. También está resistir política o militarmente, o dejar el país, u ocultar en un nivel de microsociedad la identidad, protegerla, por ejemplo, en la vivencia privada, familiar, con las conversaciones, lecturas, música, etc. Pero el objeto del miedo que surge el 11 de septiembre de 1973 permanece fortalecido. La liberación del terror neoliberal que se ha consolidado solo será posible modificando la identidad sociopolítica en forma radical, denominando democracia (protegida) a lo que no lo es, pensando que el nacionalismo es compartir los preceptos de la Doctrina de Seguridad Nacional, etc. Las palabras anteriores han cambiado su significado. La miseria material, los bajos sueldos, la escasez de trabajo, completan el contexto funcional al Gran Terror. Ha surgido el consenso del miedo que posibilita dejar atrás la construcción comunitaria de la sociedad, reemplazándola por una identidad individualista que cree en un esencialismo mercantil avalado por la "concepción cristiana".

\section{Esencialismo neoliberal}

El año 1979 se superan las dificultades de los años anteriores al institucionalizar mediante la Constitución de 1980 el ejercicio de la violencia mediante la legalización de los presupuestos básicos de la Doctrina de Seguridad Nacional. Las disidencias en torno a la Carta Fundamental generan en parte el desplazamiento de los gremialistas del poder, pero no de los neoliberales, que imponen su modelo con más profundidad buscando generar "modernizaciones sociales" Vergara, 1985: 215-230). Se acude a la "concepción cristiana" para sustentarla en la trascendencia, amparándose directamente en la Declaración de Principios, evitando así mayores desarrollos: se une el hombre a ella por su espiritualidad y, está por sobre el Estado, quien debe respetar el Principio de Subsidiariedad. No existen mayores detalles intermedios o complementarios de los elementos trascendentes mencionados; la proyección buscada es concreta, en la inmanencia. Se afirma sobre la "concepción cristiana" que una "visión global de la realidad nacional no puede omitir una referencia a la posición de lo religioso en la nueva constitucionalidad". Cita a la Declaración de Principios por ser "explícita" en este punto, al señalar que "en consideración a la tradición patria y al pensamiento de la inmensa mayoría de nuestro pueblo, el Gobierno de Chile respeta la concepción cristiana sobre el hombre y la sociedad". Agrega: "De allí el concepto del hombre como ser dotado de espiritualidad, con todas las connotaciones del más alto nivel doctrinario y jurídico que ello envuelve. Consecuentemente, al autodefinirse como Estado nacionalista, humanista y cristiano, Chile 
se pronuncia rotundamente incompatible con el materialismo, pues no es posible defender tales principios sin combatir a este, enemigo total de esos valores y de las bases mismas de la civilización occidental y cristiana" (47). También, que “...enfrentados a la expansión gigantesca del marxismo soviético, sería anacrónico o ciego querer preservar los fundamentos libertarios y cristianos de Chile, y sostener al mismo tiempo que no es indispensable actuar combativamente contra aquel, que constituye una desfiguración consciente, metódica e integral de cada uno de los principios cristianos. En modo alguno significa esto que la nueva institucionalidad propugne la intolerancia religiosa o el sectarismo. El Acta Constitucional $\mathrm{N}^{\circ} 3$ categóricamente asegura a todas las personas la libertad de conciencia, la manifestación de todas las creencias y el ejercicio libre de todos los cultos que no se opongan a la moral, a las buenas costumbres o al orden público, honrando así una larga tradición de tolerancia... Sin embargo, preciso es tener conciencia que todas las creencias por igual se ven amenazadas de desaparecer por el marxismo, que se autoerige en una pseudoreligión tan pronto controla el poder total" (47).

Al igual que la Declaración de Principios, se vio que Visión Futura reconoce la existencia de "la espiritualidad y dignidad de la persona humana", con lo que confirma su vínculo con la "concepción cristiana". Pero no existe un mayor desarrollo de este punto, aunque en dos de sus consecuencias se realiza la proyección concreta de lo mencionado al expresar que el Estado "es un instrumento que debe estar al servicio de la persona, contrariamente a lo que propugnan las doctrinas estatistas y socializantes. Su finalidad es el bien común general, definido como aquel conjunto de condiciones sociales que permita a todos y cada uno de los chilenos alcanzar su plena realización personal" (22), no refiriendo, como la Declaración de Principios, que el Estado tiene un poder limitado por el "Bien Común", que es el vínculo entre la sociedad y el hombre pero debe respetar el Principio de Subsidiariedad, lo que prácticamente lo despoja de un sustento trascendente más amplio y fundamentado. La proyección inmanentista del uso de la "concepción cristiana" se refleja en la forma en que se trata el "peligro" en que está la "civilización occidental". Se afirma que la "dura acción militar" del 11 de septiembre de 1973 "estuvo destinada a repudiar la obra totalitaria soviética, que entronizada en un Gobierno obediente a sus fines, lo habría llevado a un estado de destrucción de los cimientos democráticos desde sus bases, por la violencia espiritual y material (3-4). Pero también el peligro es percibido en el futuro al afirmar que la "forma de Gobierno tradicional" "lo sería nuevamente, si así se lo permitiéramos" (4), porque la "más peligrosa amenaza de nuestro tiempo" es el "marxismo soviético".

En cuanto a los aspectos económicos tratados por Visión Futura, solo se mencionan principios generales trascendentes, sin detallarlos mayormente, si se compara con lo que se hace en la 
Declaración de Principios. Con ellos se busca precisar una acción concreta en la inmanencia en términos políticos a partir del Estado; también, sus vínculos con el "principio de subsidiariedad" y la "solidaridad". Refieren con ello, y con otras menciones pasajeras, una legitimación trascendente, pero la proyección trascendente neoliberal es diferente pues su programa económico se fundamenta en un saber de carácter científico, la ciencia económica moderna, por lo que para ellos las críticas a la política económica serían fruto de la ignorancia o la defensa de intereses particulares. Se genera una concepción tecnocrática del poder que sacraliza a los expertos, quienes son los únicos capaces de conducir a la sociedad hacia un nuevo orden. No se incluye a los gremios, cuya participación se convierte en un obstáculo, pues defienden solo intereses parciales y no universales. De igual forma se ven los planeamientos de toda organización corporativa o política. Sin embargo, es esta suerte de creencia en la cientificidad de sus planteamientos la que, precisamente, les otorga un tono trascendente, uno en que la terminología a ratos es diferente, de corte económico, aunque recogiendo la de la Declaración de Principios, variando su significado. Por ello, si bien hay alusiones a anteriores elementos, pese a que los gremialistas los hayan adaptado conceptualmente a la verdad necesaria a las concepciones tecnocráticas del poder, estos quedan sin un fondo conceptual sólido. Sin duda, deben usarse, porque remiten a conceptos que, por provenir, al menos, de la Declaración de Principios, otorgan una consistencia temporal conceptual al régimen y, en cuanto a la hermandad antes mencionada, mantienen una estructura de significación que permite su pervivencia y unidad de sentido y consolidan su ideología de sinsentido. Por ejemplo, cuando José Piñera expresa en diciembre de 1980 que el régimen militar haría "la última revolución, la libertaria, aquella que al arrebatar el poder al Estado y devolverlo a los individuos, terminaría con todas las revoluciones (Vergara, 1985: 99-100 y 229), no quiere con ello significar igual sentido de "revolución" que el planteado en la Declaración de Principios en 1974. La base doctrinal trascendente de cada uno es distinta.

La utilización de los elementos trascendentes del nacionalismo que se expone en Visión Futura una mínima exposición de su sentido y una aplicación inmanentista como prioridad. Se busca generar un disciplinamiento político en el presente pero también en el futuro. Los temas básicos referidos son que la "nación se encuentra dañada" y que debe "reconstruirse"; que el gobierno es "nacionalista" y que el "nacionalismo" reconoce la "espiritualidad de la persona humana. Es decir, el país está en crisis y su reconstrucción la realizará la Junta, amparada en el "nacionalismo" y en la "concepción cristiana”, nacionalismo que, políticamente, protege de influencias extranjeras. Los énfasis que sostienen la "unidad nacional" se han modificado, si se observan los documentos anteriores. En la nueva base de cohesión identitaria figuran el antimarxismo y los valores de la chilenidad. Ahí estaría el "nosotros". En todo lo demás debería funcionar el "yo", especialmente en las acciones 
económicas. Aquí está radicado el punto de llegada de la ideología del sinsentido, de su maduración para superar el terror que se desarrolla desde 1973.

La Constitución de 1980 recoge esta paradoja, en cuanto a que el enunciado de los elementos trascendentes permite una múltiple interpretación, cuando lo que predomina doctrinalmente en la élite gobernante es el neoliberalismo. Ello es funcional a su proyecto. En el artículo $1^{\circ}$, se "invoca" "el nombre de Dios Todopoderoso" para decretar la aprobación de la Constitución. Los cuatro primeros incisos del artículo $1^{\circ}$ recogen principios de doctrina cristiana, que son protegidos. Los contrarios son considerados antivalores de la institucionalidad del Estado, pero no se establecen sanciones ni se especifica qué debe cumplirse, lo que ya indica, al igual como lo hiciera la Declaración de Principios, que, de hecho, esta falta de precisión establece una separación entre las realidades inmanentes y trascendentes. Durante el predominio neoliberal, ello es funcional al ejercicio del poder político, como en 1974, cuando las hegemonías aún no se definían. Entonces, al igual que en 1980, nunca se define o precisa en qué consiste "la concepción cristiana sobre el hombre o la sociedad". Ello deja abierto el camino para adaptarla en cuanto a enunciado a sus propias necesidades coyunturales, para proyectar flexiblemente un discurso productor de terror. Lo único que siempre queda en claro, implícitamente, en un plano simbólico, en ambos documentos, es que es la cercanía al Dios cristiano lo que protege al país y que esto es lo que "la inmensa mayoría", el "pueblo", desea. Pero, en un plano más concreto, inmanente, se mantiene la noción de que " $\mathrm{El}$ Hombre Tiene Derechos Naturales Anteriores y Superiores al Estado", y que estos, "no siendo él quien los concede, tampoco podría jamás negarlos". Sin embargo, el hecho de que "deba reconocerlos" y "reglamentarlos", implica ponerlos en la historia según su poder, dejando latente la posibilidad de desconocerlos y de manipularlos.

\section{Conclusión}

Hacia el año 1979, el RCM expone discursivamente un documento oficial, Visión Futura de Chile, desde la autoría de su líder, el general Augusto Pinochet, procurando, como el título lo expresa, perfilar el futuro del país. Sin embargo, en él se articulan miedos diferentes, en tiempos distintos, para generar un consenso del miedo que permita un disciplinamiento sociopolítico emocional funcional a la etapa final fundacional -neoliberal, de la Doctrina de Seguridad Nacional-que se procura implantar. Los miedos del pasado lo son a la oligarquía parlamentaria que perturbó al Presidente de la República en el siglo XIX e inicios del XX, y, más recientemente, al marxismo, que con el gobierno de la Unidad Popular debilitó a la Patria. También son del presente, al marxismo cubano y soviético, a la democracia liberal que puede generar condiciones en que la Unidad Popular reviva, y a las elites civiles de derecha que discuten la Constitución de 1980, lo que se expresa en cuanto que perturban o impiden al Presidente de la Re- 
pública desarrollar sus tareas. Los miedos al futuro inmediato son que la concepción cristiana gremialista de la Declaración de Principios de 1974 pueda permear el nuevo esencialismo del mercado neoliberal, y que la política interfiera su funcionamiento. Para los militares, que no se concrete el tutelaje sobre los civiles. Para la aprehensión emocional de estos elementos cognitivos la miseria económica y la brutal represión sociopolítica constituyen un contexto de inseguridad que, desde 1973, han generado una acumulación desinsibilizadora que ha escalado a biopoder en sus efectos, llegando a percibirse que el ejercicio de esta violencia aséptica contra el enemigo interno otorga seguridad, es decir, se ha construido una ideología del sin sentido que permite convivir con un objeto del miedo del que sólo es posible adaptarse, pero no controlarlo o ausentarlo. La utopía de un mercado ordenador que articule una comunidad sin soberanía ilustrada refleja como desde el cuerpo una emoción, el miedo, lee patológicamente el entorno sociopolítico para, sin embargo, dar plausibilidad a un régimen que produce terror sistemáticamente $\mathrm{y}$, con ello, encontrar seguridad. El consenso emocional así alcanzado en parte de la población, no sólo por la elite civil y militar que sostiene al RCM, demuestra que en esta fuga al futuro para huir del terror se permanece más profundamente en él.

\section{Referencias citadas:}

Barrancos, D. (2014): “Sentidos, sentimientos y sensibilidades (1880-1930)”. Revista Latinoamericana sobre Cuerpos, Emociones y Sociedad. $\mathrm{N}^{\circ} 15$. Año 6. Agosto-Noviembre. Argentina.

Bauman, Z. (2004): “La sociedad sitiada”. F.C.E., México.

Bauman, Z. (2007) “Miedo Líquido”, Buenos Aires, Paidós.

Bourke, J. (2006): “Fear. A Cultural History”. Shoemaker \& Hoard Edition, EE.UU.

Burke, P. (2005): "Is There a Cultural History of the Emotions?” En: Gouk, Penelope y Hills, Helen. Representing Emotions: New Connections in the Histories of Art, Music and Medicine. Aldershot: Imprint Ashgate.

Camps, V. (2011): "El Gobierno de las emociones". Barcelona: Herder.

Chóliz, M. (2005): "Psicología de la emoción: el proceso emocional”. Departamento de Psicología Básica. Universidad de Valencia.

Constitución de 1980. (1981): Editorial Jurídica de Chile. Segunda Edición, mayo.

“Declaración de Principios de la Junta de Gobierno". (1974): Editora Nacional Gabriela Mistral, Santiago.

Delumeau, J. et al. (2002): "El miedo. Reflexiones sobre su dimensión social y cultural”. C. R., Medellín.

Diel, P. (1995): “La Angustia”. FCE, México. 
Donatello, L. (2010): “Catolicismo y montoneros. Religión, política y desencanto”. Eds. Manantial, Buenos Aires.

Escalante, F. (1990): “La política del terror, apuntes para una teoría del terrorismo". México, FCE.

Feierstein, D. (2012): “Memorias y Representaciones: sobre la elaboración del genocidio". FCE, Buenos Aires.

Frühling, H. (2002): "Violencia e inseguridad en el Chile moderno". En: Rojas, Francisco-Goucha, Moufida. Seguridad Humana, Prevención de Conflictos y Paz en América Latina y el Caribe. FLACSO Chile.

Gonzalez, X. (2013): "El manejo de las emociones entre los autores pragmatistas: el inicio de la emoción situada. Revista Electrónica de Psicología Iztacala. 16, (4), UNAM, México.

Harrington, E. y González, M. (1987): “Bomba en una Calle de Palermo". Editorial Emisión, Santiago.

Korstanje, M. (2011): "La Fobología, ¿ciencia o forma de entretenimiento?" Nómadas. Revista Crítica de Ciencias Sociales y Jurídicas. Vol 31, Universidad Complutense, Madrid.

Lira, E. y Castillo, M. (1991): "Psicología de la amenaza política y del miedo". Instituto Latinoamericano de Salud Mental y Derechos Humanos. Ediciones ChileAmérica CESOC, Santiago.

Malerba, J. (2013): “Ensayos Críticos: Teoría, Histo- ria y Ciencias Sociales". Protohistoria Ediciones, Rosario.

Maureira, F. y Sánchez, C. (2011): "Emociones biológicas y sociales”. Santiago. Revista Gaceta de Psiquiatría Universitaria 7, Universidad de Chile.

Mensaje Presidencial. (1979).

Mongardini, C. (2007): “Miedo y Sociedad”. Madrid: Alianza Editorial.

Moraña, M. (2012): "Postscriptum. El afecto en la caja de herramientas". En: El Lenguaje de las emociones. Afecto y cultura en América Latina. Moraña, Mabel-Sánchez, Ignacio. Ed. Iberoamericana, Madrid.

Nussbaum, M. (2006): "El ocultamiento de lo humano. Repugnancia, Vergüenza y ley". Katz Editores, Buenos Aires.

Pacheco, L. (2011): “Las emociones y la moral. Una propuesta desde la psicología". Trabajo para optar al título de Psicóloga. Universidad Nacional de Colombia. Sede Bogotá.

Pellegrino, U. (1983): "Diccionario Teológico Interdisciplinar". Salamanca: Ediciones Sígueme, tomo IV.

Plamper, J. (2014): "Historia de las emociones: caminos y retos". Madrid: Cuadernos de Historia Contemporánea, vol. 36, Universidad Complutense de Madrid.

Ramos, C. (1985): “Caudillismo e Ilustración: Ele- 
mentos Socioculturales para la Comprensión del Liderazgo Político en América Latina”. Estudios Sociales, CPU, $\mathrm{N}^{\circ} 22$.

Reber, D. (2012): “La afectividad epistémica: el sentimiento como conocimiento en El secreto de sus ojos y La mujer sin cabeza”. En: Moraña, Mabel y Sánchez, Ignacio. El lenguaje de las emociones. Afecto y cultura en América Latina. Madrid: Editorial Iberoamericana.

Rodríguez, T. (2006): "El Valor de las emociones para el análisis cultural”. Papers 87, 2008.

Rosenwein, B. Emotional Communities in the Early Middle Ages. New York, Cornell University Press.

Shsurko, Y. y Shkurko, A. (2014): "Emotions and Cognitions in Social Relationships: A Neurosociological Approach". Revista Latinoamericana de Estudios sobre Cuerpos, Emociones y Sociedad. $N^{\circ} 15$, agosto-noviembre, Argentina.

Stearns, P. y Stearns, C. (1985): “Emotionology: clarifying the History of Emotions and Emotional Standards". American Historical Review 90, Oxford University Press.

Timmermann, F. (2005): "El Factor Pinochet. Dispositivos de Poder, Legitimación, Elites. Chile, 19731980”. Ediciones Universidad Católica Silva Henríquez. Santiago.

Timmermann, F. (2007): “Su Más Amargo Cáliz. El Cardenal Silva Henríquez Frente a la Violencia del
Régimen Cívico-Militar. Chile, 1973-1975”. Revista de Historia y Geografía, $\mathrm{N}^{\circ} 21$, Univ. Católica Silva Henríquez.

Timmermann, F. (2015a): "El Gran Terror. Miedo, emoción y discurso. Chile, 1973-1980”. Editorial Copygraph, Santiago.

Timmermann, F. (2015b): “Miedo, Emoción e Historiografía”. Revista de Historia Social y de las Mentalidades. Universidad de Santiago de Chile. Departamento de Historia, Volumen 19, $\mathrm{N}^{\circ} 1$.

Valdivia, V. (2003): “El Golpe Después del Golpe. Leigh vs. Pinochet. Chile 1960-1980”. LOM Ediciones, Santiago.

Vergara, P. (1985): “Auge y Caída del Neoliberalismo en Chile”. FLACSO, Santiago.

Zaragoza, M. (2013): "Historia de las emociones: una corriente historiográfica en expansión" Madrid, ASCLEPIO: Revista de Historia de la Medicina y de Ciencia 65, Consejo Superior de Investigaciones Científicas. Centro de Estudios Históricos.

\section{Notas:}

1Por ejemplo, luego que el estímulo llega al tálamo desde los sentidos, la vía talámica indirecta funciona 300 milisegundos después de la talámica directa, que actúa en niveles bajos de conciencia (Maureira-Sánchez, 2007: 186).

${ }^{2}$ Las emociones están vinculadas en su manifesta- 
ción a conocimiento, específicamente a creencias. "El temor involucra la creencia en la posibilidad de que es inminente que algo malo ocurra en el futuro”. La emoción misma puede ser valorada, pero si no estuviera relacionada con creencias, "si fueran simplemente impulsos irreflexivos, como corrientes eléctricas, entonces un padre o un maestro sólo podría influir en las emociones de un niño a través de un proceso de condicionamiento de su conducta, a la manera en que se enseña a una rata a recorrer su laberinto" (Nussbaum, 2006).

${ }^{3}$ El rol de los civiles iguala o sobrepasa al de los militares. El gremialismo dirigido por Jaime Guzmán fue el partido político no oficial que, entre otros, organizó el espacio administrativo -municipalidades, regionalización, etc.- y el neoliberalismo dirigido por Sergio de Castro sus políticas económicas. Habría que agregar, entre otros, el papel que cumplieron los civiles en el Poder Judicial, Ministerio de Educación y prensa, y también el grupo Patria y Libertad en los organismos de seguridad. La Declaración de Principios del Gobierno de Chile, documento fundacional del RCM, habla incluso, en un comienzo, de formar "un nuevo y gran movimiento cívico militar" (1974, p. 29). También se habla de golpe cívico-militar (GCM, en adelante). La rápida ruptura del orden político que se produjo el 11 de septiembre de 1973, realizada por medio de una violencia extrema, lleva a visualizar la ejecución de un "golpe de fuerza". Cívico-militar, porque si bien la instancia final de ejecución fue mayormente militar, las condiciones previas de ingobernabilidad funcionales para ello fueron preparadas por civiles, principalmente de la Derecha y Centro político, apoyados por Estados Unidos y Brasil.
4En la inmanencia, el ser queda inscrito en lo experimentable o finito y su realización o ejercicio no pone al efecto como existente fuera de ella, donde el viviente es a la vez agente y paciente o sujeto actuado. Trascendencia son las experiencias que sobrepasen los límites que señala la inmanencia (Pellegrino, 1983: 543-555). 